\title{
A novel multilayer composite structured thermoelectric module with high output power
}

Xue Wang ${ }^{1}$, Hongchao Wang ${ }^{*}, 1$, Wenbin $\mathrm{Su}^{1}$, Teng Wang ${ }^{1}$, María A. Madre ${ }^{2}$, Jinze Zhai ${ }^{1}$, Tingting Chen ${ }^{1}$, Andres Sotelo ${ }^{*}, 2$ and Chunlei Wang ${ }^{*}, 1$

${ }^{1}$ School of Physics, State Key Laboratory of Crystal Materials, Shandong University Jinan 250100, P. R. China

${ }^{2}$ ICMA (CSIC-Universidad de Zaragoza), María de Luna, 3. 50018 Zaragoza, Spain

\begin{abstract}
Output power is a vital criterion in evaluating the heat-electricity conversion capability of thermoelectric power generators (TEGs). This study firstly proposes a novel $(\mathrm{Bi}, \mathrm{Sb})_{2} \mathrm{Te}_{3}$-based multilayer composite structured thermoelectric module (MCTEM) that can achieve high power output. Parallel heat transfer and electrical parallel connection are simultaneously achieved in an n-type single-leg MCTEM which composed of several alternately stacked thermoelectric slices and inner electrodes. The extremely low inner resistance $\left(R_{\text {in }}\right)$ and high current $(I)$ are 0.03 and 12.7 times of those measured in single-leg traditional modules, respectively, then a maximum output power $\left(P_{\max }\right)$ of $5.8 \mathrm{~mW}$ is achieved at $\Delta T=35^{\circ} \mathrm{C}$. The effect of the number of slices on module performance has been investigated, and the optimal $P_{\max }$ for $\mathrm{n}$ - and p-type single-leg MCTEMs have been achieved when using 3 slices. Based on the optimized single-leg MCTEMs above mentioned, a $\pi$-type MCTEM has been designed to improve the output voltage $(V)$ and further enhance $P_{\max }$. The $\pi$-type MCTEM achieves a high $V$ of $3.1 \mathrm{mV}$ while keeping a low $R_{\text {in }}$ of $0.94 \mathrm{~m} \Omega$ and large $I$ of 3.3 A at $\Delta T=35^{\circ} \mathrm{C}$, and a $P_{\max }$ of 10.5 $\mathrm{W}$ which is 4.2 times of traditional module. This new design of MCTEM provides enlightenment for the fabrication and commercialization through the development of high-power TEGs.
\end{abstract}


Keywords: Thermoelectric power generator; Multilayer composited structure; Parallel connection of heat and electricity; High output power; Geometry optimization. 


\section{Introduction}

Enormously large amount of low-quality waste heat produced by human activities cannot be effectively utilized, leading to huge energy waste ${ }^{1}$. Such as the spent fuel pool of nuclear power plants which can be regarded as a large low-quality waste heat source because the temperature of cooling water is always below $60{ }^{\circ} \mathrm{C}$. If this huge waste heat can be transferred to useful electric power, the self-powered cooling system will be formed to keep the safe temperature of spent fuel and prevent accidents when outside power is off, thereby achieving good social and economic benefits. Thermoelectric power generator (TEG), which can achieve the transformation between heat and electricity is a desired technology to recover huge low-quality heat ${ }^{2,3}$. So many efforts have been done to study TEGs and researchers expect that more electric power can be produced through their optimization.

The $\pi$-type traditional thermoelectric module (TTEM), the key part of TEGs, commonly consists of $\mathrm{n}$ - and p-type thermoelectric legs with cuboid or cylindrical shape. These legs are electrically connected in series and thermally in parallel ${ }^{4,5}$. This TTEM easily conducts heat unidirectionally and produces large temperature difference in $\mathrm{z}$-axis, which allows achieving high module performance ${ }^{6-8}$. However, the real applications of TEGs are limited due to their relatively low output power. Thus, structural design, geometric structural modifications and other optimization methods have been focused to optimize power output ${ }^{9}$. For example, Fan et al. established an annular thermoelectric device. This type of annular structure is applicable for non-flat heat sources, can achieve efficient heat transfer and obtain high output power ${ }^{10}$. Liu et al. investigated the effect of asymmetrical legs on the performance of a $\mathrm{PbTe}$-based thermoelectric generator. The results showed the variable cross-section structure could enhance the temperature gradient inside the legs, significantly increasing the electric 
potential and output power. When the leg length ratio and cross-sectional area ratio are, respectively, 1.31 and 5.67, the output power can be increased by $4.21 \%$ as compared with the classical design ${ }^{11}$. Considering these series of thermoelectric systems, the damage of one thermoelectric leg will lead to the failure of the thermoelectric system. To ensure a sufficient output power and improve the reliability, Suda Hiroshi et al. designed a thermoelectric conversion module where the thermoelectric legs are electrically connected in parallel. This structure of electric parallel connection can achieve a low inner resistance and high current, and then obtain a sufficient output power under ideal conditions. However, this thermoelectric system depends on a complex assembly circuit which has low integration and serious thermal radiation losses between different legs ${ }^{12}$. Thus, new designs are urgently needed for further improving of power output to meet the requirements of electrical devices.

Thermoelectric material is another key factor in terms of the performance of thermoelectric devices. For the low-temperature heat resources, the temperature range is always below $200{ }^{\circ} \mathrm{C} . \mathrm{Bi}_{2} \mathrm{Te}_{3}$ and $\mathrm{Sb}_{2} \mathrm{Te}_{3}$-based alloys are traditional low-temperature thermoelectric materials, which possess superior thermoelectric properties in this temperature range ${ }^{13,14}$. Among these $(\mathrm{Bi}, \mathrm{Sb})_{2} \mathrm{Te}_{3}$-based materials, the n-type $\mathrm{Bi}_{2} \mathrm{Te}_{2.79} \mathrm{Se}_{0.21}{ }^{15}$ and p-type $\mathrm{Bi}_{0.5} \mathrm{Sb}_{1.5} \mathrm{Te}_{3}{ }^{16}$ alloys, as the most typical material compositions, have achieved the maximum figure of merit (ZT) of 1.2 at $84{ }^{\circ} \mathrm{C}$ and 1.4 at $100{ }^{\circ} \mathrm{C}$, respectively. Considering these $(\mathrm{Bi}, \mathrm{Sb})_{2} \mathrm{Te}_{3}$-based thermoelectric materials, the above-mentioned geometric optimization methods, and a highly integrated parallel structure in form of a layered composite structure ${ }^{17,18}$, a novel multilayer composite thermoelectric module (MCTEM) has been designed. Parallel heat transfer and electrical connection are simultaneously achieved in the MCTEM. Then, low inner resistance $\left(R_{\text {in }}\right)$, large current $(I)$, and super output power $(P)$, are obtained. Moreover, 
through optimizing the number of slices, and applying a $\pi$-type connection, $\pi$-type MCTEMs have been constructed using n-type $\mathrm{Bi}_{2} \mathrm{Te}_{2.79} \mathrm{Se}_{0.21}$ or p-type $\mathrm{Bi}_{0.5} \mathrm{Sb}_{1.5} \mathrm{Te}_{3}$ single-leg MCTEMs, composed by 3 slices have been designed. The $\pi$-type MCTEM can shows low $R_{\text {in }}(0.94 \mathrm{~m} \Omega)$, high output voltage $(3.1 \mathrm{mV})$, and large $I(3.3 \mathrm{~A})$ with $\Delta T$ of $35^{\circ} \mathrm{C}$. Then, the maximum obtained output power $(10.5 \mathrm{~W})$ is 3.2 times higher than the measured in $\pi$-type TTEM, showing that the multilayer composite thermoelectric module can achieve extremely high output power.

\section{Simulation approach}

\subsection{Numerical model}

The schematic diagrams of an n-type $\mathrm{Bi}_{2} \mathrm{Te}_{2.79} \mathrm{Se}_{0.21}$ single-leg MCTEM and TTEM are illustrated as examples in Figure 1. Both modules have the same dimensions, the lengths in $\mathrm{x}, \mathrm{y}$ and $\mathrm{z}$ directions are, respectively, $2.5 \mathrm{~mm}, 2 \mathrm{~mm}$ and 5.6 $\mathrm{mm}, l_{\mathrm{x}} \times l_{\mathrm{y}} \times l_{\mathrm{z}}=2.5 \times 2 \times 5.6 \mathrm{~mm}^{3}$. These two modules are composed of two $\mathrm{Al}_{2} \mathrm{O}_{3}$ ceramic substrates, two external $\mathrm{Ag}$ electrodes and an n-type $\mathrm{Bi}_{2} \mathrm{Te}_{2.79} \mathrm{Se}_{0.21}$ thermoelectric element. The dimensions of $\mathrm{Al}_{2} \mathrm{O}_{3}$ ceramic substrates and external electrodes for the two modules are $2.5 \times 2 \times 0.2 \mathrm{~mm}^{3}$ and $2.5 \times 2 \times 0.1 \mathrm{~mm}^{3}$, respectively. The design of $\mathrm{n}$ type $\mathrm{Bi}_{2} \mathrm{Te}_{2.79} \mathrm{Se}_{0.21}$ thermoelectric elements is the major difference between the MCTEM and TTEM, as shown in Figure 1. The thermoelectric element of the TTEM is a cuboid with the size of $2.5 \times 2 \times 5 \mathrm{~mm}^{3}$. As the novel single-leg MCTEM shown in Figure 1(a), the thermoelectric element is designed as a layered composite structure consisting of alternating layers of inner electrodes and thermoelectric materials along the $\mathrm{x}$-axis. In here, the total sizes including thermoelectric slices and inner electrodes are the same as the thermoelectric leg in TTEM, which was fixed at $2.5 \times 2 \times 5 \mathrm{~mm}^{3}$. The dimension of inner electrodes is $0.1 \times 2 \times 4.9 \mathrm{~mm}^{3}$, and the number is one more than that 
of thermoelectric slices. Each inner electrode has a $0.1 \mathrm{~mm}$ space in $\mathrm{z}$ direction to reach the external electrode. These spaces are connected alternatively to the upper or lower part of the module. In this case, the first, third and fifth inner electrodes (cold-side inner electrodes) are connected with the upper external electrode, the second and fourth inner electrodes (hot-side inner electrodes) are connected to the lower external electrode, as presented in Figure 1(a). Based on the MCTEM with invariable volume, the dimensions for one thermoelectric slice are depending on the number $(N)$, as $(2.4 / N-$ $0.1) \times 2 \times 5 \mathrm{~mm}^{3}$. For example, the number of n-type thermoelectric material slices $\left(N_{\mathrm{n}}\right)$ is 4 in the schematic, and the size of one slice is $0.5 \times 2 \times 5 \mathrm{~mm}^{3}$. In order to try to determine the performance of such module, the reported experimental temperature-dependent thermoelectric properties of n-type $\mathrm{Bi}_{2} \mathrm{Te}_{2.79} \mathrm{Se}_{0.21}$ have been used in the simulation process, and are presented in Figure S1. The physical properties of $\mathrm{Al}_{2} \mathrm{O}_{3}$ and $\mathrm{Ag}$ are given in Table S1.

\subsection{Finite-element simulation}

The relationship between thermoelectric module design and physical properties is focused. Some boundary conditions and reasonable assumptions are adopted. Firstly, the thermoelectric module is considered to be in steady state. Secondly, the thermoelectric module is regarded as an adiabatic system where the heat radiation and convection on all surfaces are ignored. Thirdly, the temperature of the cold side $\left(T_{\mathrm{c}}\right)$ is fixed at room temperature $\left(25^{\circ} \mathrm{C}\right)$. The temperature of the hot side $\left(T_{\mathrm{h}}\right)$ changes from 35 ${ }^{\circ} \mathrm{C}$ to $60{ }^{\circ} \mathrm{C}$, because the temperature of most low-quality waste heat is relatively low, only a little bit higher than room temperature. Fourthly, electrical and thermal contacts are considered as ideal in this theoretical design. Fifthly, the upper external electrode is connected to the ground, and the lower external electrode is set to the terminal.

Based on these boundary conditions and assumptions, the thermal and electrical 
behaviors can be described by the following governing equations.

$$
\begin{aligned}
& \boldsymbol{\nabla} \cdot \boldsymbol{q}=\nabla \cdot\left(-\kappa(T) \nabla T+P_{\mathrm{c}}(T) \boldsymbol{J}\right)=\boldsymbol{J}^{2} / \sigma(T) \\
& \boldsymbol{\nabla} \cdot \boldsymbol{J}=\boldsymbol{\nabla} \cdot(-\sigma(T)(\nabla V+S(T) \nabla T))=0
\end{aligned}
$$

where, $\boldsymbol{q}$ is the heat flux vector, and $\boldsymbol{J}$ is the current density vector. $S(T), \sigma(T), \kappa(T)$ and $P_{\mathrm{c}}(T)$ are the temperature-dependent Seebeck coefficient, electrical conductivity, thermal conductivity and Peltier coefficient calculated by $S(T) T$, respectively. $\nabla T$ and $\nabla V$ are the temperature and electric potential gradients.

As following, the electromotive force $(E), R_{\mathrm{in}}, V, I$ and $P$ can be obtained. For the single-leg MCTEM, the $E$ equals the electric potential generated by a single thermoelectric slice due to the electrical parallel connection.

$E=\int S(T) d T$

The $R_{\text {in }}$ is strongly depended on the $N$, which will be confirmed as follows,

$R_{\text {in }}=\left(\left(R_{\mathrm{s}}+R_{\mathrm{i}}\right)\left(R_{\mathrm{s}}+3 R_{\mathrm{i}} / 2\right) /\left(N R_{\mathrm{s}}+(3 N / 2-1) R_{\mathrm{i}}\right)\right)+2 R_{\mathrm{e}}$

Here, the $R_{\mathrm{s}}, R_{\mathrm{i}}$ and $R_{\mathrm{e}}$ refer to the resistance of a thermoelectric slice, an inner electrode and an external electrode, respectively. In here, the temperature-dependence of $\mathrm{Ag}$ resistance is not considered. Once the thermoelectric module is connected with an external load resistance $\left(R_{\mathrm{L}}\right)$ to form a loop, $V$ and $I$ can be obtained as follows.

$$
\begin{aligned}
& V=E R_{\mathrm{L}} /\left(R_{\mathrm{in}}+R_{\mathrm{L}}\right) \\
& I=E /\left(R_{\mathrm{in}}+R_{\mathrm{L}}\right)
\end{aligned}
$$

Finally, the output power is calculated using the calculated $V$ and $I$.

$$
P=E^{2} R_{\mathrm{L}} /\left(R_{\mathrm{in}}+R_{\mathrm{L}}\right)^{2}
$$

And the $P_{\max }$ is obtained when the inner resistance and load resistance are equal. 


\section{Results and discussions}

\subsection{The performance of an n-type single-leg MCTEM}

Figure 2(a) shows the temperature distribution in a n-type single-leg MCTEM under the open-circuit condition at $\Delta T=35{ }^{\circ} \mathrm{C}\left(T_{\mathrm{c}}=25{ }^{\circ} \mathrm{C}, T_{\mathrm{h}}=60{ }^{\circ} \mathrm{C}\right)$. The temperature is changed in the $\mathrm{x}$ - and $\mathrm{z}$-axis, and remains constant in the $\mathrm{y}$-axis. Along the $\mathrm{x}$-axis, the temperature changes alternately between low-temperature and hightemperature zones. In the $\mathrm{z}$ direction, the temperature decreases with increasing module height. In detail, Figure 2(b) depicts the temperature distribution at xy cross-section when the $l_{\mathrm{z}}$ is $2.8 \mathrm{~mm}$. Because of the high thermal conductivity of $\mathrm{Ag}$, the hot-side inner electrodes have higher temperature $\left(T_{\mathrm{e}-\mathrm{h}}\right)$ and cold-side inner electrodes have lower temperature $\left(T_{\mathrm{e}-\mathrm{c}}\right)$, when compared to the adjacent thermoelectric slices. In other words, the adjacent hot-side and cold-side inner electrodes can be regarded as the hot and cold ends, respectively, for one thermoelectric slice. Thus, there is a horizontal temperature difference in the two sides of each thermoelectric material slice. The power is directly generated by this temperature difference across the thermoelectric material. So, this temperature difference is noted as an effective temperature difference $\left(\Delta T_{\mathrm{e}}\right)$ in a single-leg MCTEM. The $\Delta T_{\mathrm{e}}$ for each thermoelectric slice is slightly different, as shown in xy cross-section temperature distribution graph. For example, the $T_{\mathrm{e}-\mathrm{c}}$ for the second and third thermoelectric slices shows the same profile, and it will be strongly affected by two adjacent hot-side inner electrodes. So the $T_{\mathrm{e}-\mathrm{c}}$ for the second and third thermoelectric slices is slightly higher than those of first and fourth thermoelectric slices, and then their $\Delta T_{\mathrm{e}}$ is about $2.8^{\circ} \mathrm{C}$ lower when $\Delta T$ is $35^{\circ} \mathrm{C}$. In this cross-section temperature distribution, the different $\Delta T_{\mathrm{e}}$ of four thermoelectric slices are averaged, and the average value of the single-leg MCTEM is about $11^{\circ} \mathrm{C}$. As Figure 2(a) shows, the heat flux is also flowing along the z-axis, so the $T_{\mathrm{e}-\mathrm{c}}$ and $T_{\mathrm{e}-\mathrm{h}}$ for each thermoelectric 
slice are also changed along this axis. The average $\Delta T_{\mathrm{e}}$ for these four thermoelectric slices in the xy cross-section of any height (z-axis) are almost the same, around $11{ }^{\circ} \mathrm{C}$. Therefore, in this single-leg MCTEM, the average $\Delta T_{\mathrm{e}}$ at the thermoelectric materials is about $11^{\circ} \mathrm{C}$ under $\Delta T=35^{\circ} \mathrm{C}$. This situation is largely different when compared to the single-leg TTEM considering $\Delta T_{\mathrm{e}}$ close to $35^{\circ} \mathrm{C}$, as shown in Figure S2(a). The parallel connection of heat is the main reason for the relatively lower $\Delta T_{\mathrm{e}}$ of single-leg MCTEM. In addition, the average $T_{\mathrm{e}-\mathrm{h}}$ and $T_{\mathrm{e}-\mathrm{c}}$ for all thermoelectric slices under different $\Delta T$ are shown in Figure 2(c). The $T_{\text {e-c }}$ increases from $28{ }^{\circ} \mathrm{C}$ to $35{ }^{\circ} \mathrm{C}$, while $T_{\text {e-h }}$ increases from $31{ }^{\circ} \mathrm{C}$ to $46{ }^{\circ} \mathrm{C}$ when the $\Delta T$ changes from $10{ }^{\circ} \mathrm{C}$ to $35{ }^{\circ} \mathrm{C}$. In other words, the $\Delta T_{\mathrm{e}}$ for the single-leg MCTEM increases from $3{ }^{\circ} \mathrm{C}$ to $11{ }^{\circ} \mathrm{C}$ as $\Delta T$ changes. As a consequence of the parallel heat transfer produced in a single-leg MCTEM, a relatively lower $\Delta T_{\mathrm{e}}$ is obtained. The lower $\Delta T_{\mathrm{e}}$ is beneficial for contact design, as it avoids the internal thermal expansion and improves the module reliability.

Figure 3(a) shows the electric potential distribution of the n-type single-leg MCTEM in an open circuit at $\Delta T=35^{\circ} \mathrm{C}$. The electric potential is almost unchanged along the y- and z-axis, and only alternately fluctuates in high or low potential along the $\mathrm{x}$-axis. Figure 3(b) presents the electric potential distribution at xy cross-section when the $l_{\mathrm{z}}$ is $2.8 \mathrm{~mm}$. As it was previously described, the cold-side external electrode is connected to the ground, and the hot-side external electrode is set to the terminal. Then, the cold-side and hot-side inner electrodes are almost at zero potential and highest potential, respectively. In this case, the electric potential on a thermoelectric slice is increased from the cold-side inner electrode to the hot-side inner electrode as shown in Figure 3(b). For the single-leg MCTEM, the electric potential alternately changes along the $\mathrm{x}$ direction, strongly depending on the temperature distribution shown in Figure 2(b) due to the Seebeck effect. This behavior of electric potential distribution indicates 
that these thermoelectric slices are electrically connected in parallel. This parallel connection is largely different to the series connection of single-leg TTEM shown in Figure S2(b). Because of this parallel connection, the electric potential of the single-leg MCTEM is equivalent to that generated from a thermoelectric slice. From the Formula (3), it can be deduced that large temperature differences will lead to high electric potential differences. As it has been already mentioned, the average $\Delta T_{e}$ on a thermoelectric slice is smaller, as presented in Figure 2(b), than the obtained in classical single-leg module. Consequently, the electric potential difference of the singleleg MCTEM is smaller than the determined in a single-leg TTEM (Figure S2(b)). From the above temperature and potential distributions of the single-leg MCTEM, the parallel heat transfer and electrical parallel connection are achieved, at the same time, in a single-leg module, which will beneficial for greatly increasing module performances.

Figure 4(a) shows the $V$ of the n-type single-leg MCTEM as a function of $I$ under different $\Delta T$. The $V$ linearly decreases as the $I$ increases at a fixed $\Delta T$. This $I-V$ linear relationship remains when $\Delta T$ is changed. Thus, the Ohm`s law is accomplished at any $\Delta T$, verifying the correctness of the simulation. Additionally, it is found that the slopes of all $I-V$ curves are almost same, indicating that the $R_{\text {in }}$ of the single-leg MCTEM is not significantly changed at different $\Delta T$. Figure 4(b) displays $P$ dependence on $I . P$ is improved when $\Delta T$ is increased, in the whole current ranges. At any fixed $\Delta T$, it is easy to find that $P$ firstly increases to reach a maximum, and then decreases with increasing I. At $\Delta T=35^{\circ} \mathrm{C}$, the $P_{\max }$ of $5.8 \mathrm{~mW}$ can be obtained for the single-leg MCTEM.

The $R_{\text {in }}, V, I$ and $P_{\max }$ for the n-type single-leg MCTEM at different $\Delta T$ are shown in Figure 5. Moreover, the performance of single-leg TTEM is also presented in the figure for comparison purposes. It is important to recall that both legs have the same volume $\left(2.5 \times 2 \times 5.6 \mathrm{~mm}^{3}\right)$, as previously described in Figure 1. Figure 5(a) depicts the variation 
of $R_{\text {in }}$ as a function of $\Delta T$. The $R_{\text {in }}$ of the single-leg MCTEM has not been significantly modified with the increase of $\Delta T$. The $R_{\text {in }}$ values are ranging between $0.26 \mathrm{~m} \Omega$ and 0.27 $\mathrm{m} \Omega$ at the different studied $\Delta T$. On the other hand, the values of single-leg TTEM increase from $8.5 \mathrm{~m} \Omega$ to $9 \mathrm{~m} \Omega$ when the $\Delta T$ is raised from $10{ }^{\circ} \mathrm{C}$ to $35^{\circ} \mathrm{C}$. Thus, it can be clearly seen that this single-leg MCTEM can get a lower $R_{\text {in }}$, being only about $3 \%$ of that obtained in single-leg TTEM. This effect is mainly attributed to the electrical parallel connection of this new design. Due to the inverse relationship between $R_{\text {in }}$ and $P$, as described in Section 2.2, the lower $R_{\text {in }}$ of the single-leg MCTEM will significantly push to get an excellent performance ${ }^{19,20}$. Figure 5(b) describes the $V$ dependence on $\Delta T$. The $V$ of both modules linearly enhances with increasing $\Delta T$. However, the $V$ of the single-leg MCTEM shows lower values when compared to the single-leg TTEM. The $V$ values of the single-leg MCTEM are $0.35 \mathrm{mV}$ and $1.25 \mathrm{mV}$ at $\Delta T$ of $10{ }^{\circ} \mathrm{C}$ and $35{ }^{\circ} \mathrm{C}$, respectively. This relatively low $V$ is attributed to the low $\Delta T_{\mathrm{e}}$, as it was shown in Figure 2(c). In Figure 5(c), it is noted that the $I$ of the single-leg MCTEM is much higher than that of single-leg TTEM. The value of $I$ is enhanced from 1.36 A to $4.64 \mathrm{~A}$ with the increasing of $\Delta T$ which mainly resulted from the smaller $R_{\text {in }}$ of the MCTEM. The obtained larger $I$ in the new designed module will meet the requirements of high current needed for some electrical equipment. Based on the above results, the $P_{\max }$ has been calculated and shown in Figure 5(d). The $P_{\max }$ of the single-leg MCTEM is significantly increased from $0.5 \mathrm{~mW}$ to $5.8 \mathrm{~mW}$ with enlarging $\Delta T$. At any $\Delta T$, the values of $P_{\max }$ for the single-leg MCTEM are higher when compared to the single-leg TTEM, especially at larger temperature differences. The $P_{\max }$ of the single-leg MCTEM is 4.8 times larger than that determined in single-leg TTEM at $\Delta T=35^{\circ} \mathrm{C}$. Thus, this new designed single-leg MCTEM shows lower inner resistance, leading to larger electric current and higher output power. 


\subsection{Effect of slices number on module performance}

The slice number is a key influence factor for the performance of single-leg MCTEM. There is an optimal slice number for $P$, calculated through the formula $V^{2} / R_{\text {in }}$, to reach the optimum value, because $R_{\text {in }}$ and $V$ for the single-leg MCTEM with electric parallel connection will decrease with increasing slice number ${ }^{17,21}$. Thus, the $N_{\mathrm{n}}$ of this n-type single-leg MCTEM has been optimized in this section. The $N_{\mathrm{n}}$ is set from 2 to 8 in this simulation and, consequently, the corresponding dimensions of one thermoelectric slice changes from $1.1 \times 2 \times 5 \mathrm{~mm}^{3}$ to $0.25 \times 2 \times 5 \mathrm{~mm}^{3}$. Figure 6 (a) shows the temperature distributions at the xz-plane depending on the $N_{\mathrm{n}}$ for the leftmost thermoelectric slice (1st thermoelectric slice in Figure 2) when $\Delta T$ is $35^{\circ} \mathrm{C}$. In the figure, it can be clearly seen that the high-temperature area (red area) and lowtemperature area (blue area) are decreased when increasing $N_{\mathrm{n}}$. As a consequence, the middle-temperature area is increased, leading to smaller $\Delta T_{\mathrm{e}}$. In order to quantify the $\Delta T_{\mathrm{e}}$, the $T_{\mathrm{e}-\mathrm{h}}$ and $T_{\mathrm{e}-\mathrm{c}}$ for the $1 \mathrm{st}$ thermoelectric slice, numerical data are presented in Figure 6(b). The $T_{\mathrm{e}-\mathrm{h}}$ decreases from $48.3{ }^{\circ} \mathrm{C}$ to $44.4{ }^{\circ} \mathrm{C}$ and the $T_{\mathrm{e}-\mathrm{c}}$ raises from $33.4{ }^{\circ} \mathrm{C}$ to $39.5{ }^{\circ} \mathrm{C}$ when the $N_{\mathrm{n}}$ increases from 2 to 8 . The average $\Delta T_{\mathrm{e}}$ is the difference between $T_{\mathrm{e}-\mathrm{h}}$ and $T_{\mathrm{e}-\mathrm{c}}$. In this case, it can be found the average $\Delta T_{\mathrm{e}}$ drops from $14.9^{\circ} \mathrm{C}$ to $4.9^{\circ} \mathrm{C}$ as $N_{\mathrm{n}}$ increases.

The $R_{\text {in }}, V, I$ and $P_{\max }$ values of the n-type single-leg MCTEM, as a function of $N_{\mathrm{n}}$, are depicted in Figure 7. In Figure 7(a), $R_{\text {in }}$ is reduced with a non-linear tendency at any $\Delta T$, with the increase of $N_{\mathrm{n}}$, and this trend is more obvious at relatively low $\Delta T$. This behavior is mainly due to the inverse relationship between $R_{\text {in }}$ for the single-leg MCTEM with electrical parallel connection, and $N_{\mathrm{n}}$, as calculated in Formula (4). As it can be observed in Figure 6 (b), $\Delta T_{\mathrm{e}}$ is reduced with increasing $N_{\mathrm{n}}$. Thus, $V$ is also reduced with the increase of $N_{\mathrm{n}}$ due to the Seebeck effect (Figure 7(b)). Moreover, $V$ is 
decreased from $1.9 \mathrm{mV}$ to $0.6 \mathrm{mV}$ when $N_{\mathrm{n}}$ is increased. Through the $V$ is decreased, the $I$ is still non-linearly increased when increasing $N_{\mathrm{n}}$ due to the sharply decrease of $R_{\text {in }}$, as presented in Figure 7(c). At $\Delta T=35^{\circ} \mathrm{C}, I$ raises from 3 A to 6.2 A with increased $N_{\mathrm{n}}$. Finally, the reduced $V$ and increased $I$ with increasing $N_{\mathrm{n}}$, leads to the highest $P_{\max }$ at $N_{\mathrm{n}}$ of 3 at any $\Delta T$, as shown in Figure $7(\mathbf{d})$. When the $\Delta T$ is $35{ }^{\circ} \mathrm{C}$, the $P_{\max }$ of single-leg MCTEM with $N_{\mathrm{n}}=3$ can reach $6 \mathrm{~mW}$, which is $3.4 \%$ higher than that of the single-leg MCTEM with $N_{\mathrm{n}}=4$.

On the basis of the above designed n-type single-leg MCTEM, the performance and optimization of slice number $\left(N_{\mathrm{p}}\right)$ for p-type $\mathrm{Bi}_{0.5} \mathrm{Sb}_{1.5} \mathrm{Te}_{3}$ single-leg MCTEM have also been investigated using the same simulation process. The simulated results are presented in Figure S3. The general tendencies of $R_{\mathrm{in}}, V, I$ and $P_{\max }$ are also similar to that discussed for the n-type single-leg MCTEM. This is due to the similar rules for the thermoelectric properties of n-type $\mathrm{Bi}_{2} \mathrm{Te}_{2.79} \mathrm{Se}_{0.21}$ and p-type $\mathrm{Bi}_{0.5} \mathrm{Sb}_{1.5} \mathrm{Te}_{3}$, as shown in

Figure S1. After the optimization of thermoelectric slices, the optimized $P_{\max }$ of 6.5 $\mathrm{mW}$ has been obtained at $\Delta T=35^{\circ} \mathrm{C}$ when the $N_{\mathrm{p}}$ is 3 . Consequently, the optimized $N_{\mathrm{n}}$ and $N_{\mathrm{p}}$ are same, which is due to the similar temperature distributions and material properties for n- and p-type single-leg MCTEM. In other words, these two single-leg MCTEMs have well matched and can be applied together in a large thermoelectric power generation system.

\subsection{The performance of $\pi$-type MCTEM}

As mentioned above, the single-leg MCTEM produces smaller $R_{\text {in }}$, larger $I$ and higher $P$ when compared to the single-leg TTEM. However, the $V$ of single-leg MCTEM is relatively low, which may not meet the voltage requirements of some equipment, and also limits further improvement of $P$. The $\pi$-type structure as a mostused series connection method of n- and p-type thermoelectric legs can be an adequate 
route to improve the $V$ efficiently ${ }^{22}$. Moreover, the $n$ - and p-type single-leg MCTEMs described above are well matched due to their similar materials properties and the same optimal number of thermoelectric slices. Therefore, the $\pi$-type MCTEM, combining $\pi$ type connection type, together with the new designed single-leg MCTEM has been constructed and tested here to enhance the $V$ to further improve the $P$. Figure 8 displays the schematics of the $\pi$-type MCTEM and $\pi$-type TTEM. For the $\pi$-type MCTEM, the above optimized n-type $\mathrm{Bi}_{2} \mathrm{Te}_{2.79} \mathrm{Se}_{0.21}$ single-leg MCTEM and p-type $\mathrm{Bi}_{0.5} \mathrm{Sb}_{1.5} \mathrm{Te}_{3}$ single-leg MCTEM have been used as legs of $\pi$-type MCTEM with $N_{\mathrm{n}}=N_{\mathrm{p}}=3$. For the $\pi$-type TTEM, the n-type $\mathrm{Bi}_{2} \mathrm{Te}_{2.79} \mathrm{Se}_{0.21}$ and p-type $\mathrm{Bi}_{0.5} \mathrm{Sb}_{1.5} \mathrm{Te}_{3}$ thermoelectric materials have been used as legs of module. The $\pi$-type MCTEM and TTEM have the same legs sizes of $2.5 \times 2 \times 5 \mathrm{~mm}^{3}$.

Figure 9(a) shows the temperature distribution of $\pi$-type MCTEM under the opencircuit condition when $\Delta T$ is $35^{\circ} \mathrm{C}$. The temperature distribution of $\pi$-type MCTEM is the same obtained in single-leg MCTEM, as shown in Figure 2. Moreover, the temperature distribution at xz cross-section under $\Delta T=35{ }^{\circ} \mathrm{C}$ is presented in Figure 9 (b). It can be clearly seen that the heat transport for $\pi$-type MCTEM is in parallel, in both n- or p-type single-leg MCTEM. The parallel connection of more thermoelectric slices will lead to a lower thermal resistance for this $\pi$-type MCTEM. So the $\Delta T_{\mathrm{e}}$ for $\mathrm{n}$ and p-type thermoelectric slices is, respectively, about $13.4{ }^{\circ} \mathrm{C}$ and $13.6{ }^{\circ} \mathrm{C}$ at $\Delta T=35$ ${ }^{\circ} \mathrm{C}$, which is slightly higher than that determined in single-leg MCTEM, as previously described in Figure 2(c) and 6(b). This fact is in agreement to the Fourier's law of heat conduction, where the temperature difference is inversely proportional to the thermal resistance. Figure 9(c) depicts the electric potential field under $\Delta T=35^{\circ} \mathrm{C}$. The bottom of p-type single-leg MCTEM is earthed in here. The electric potential decreases from n-type single-leg MCTEM to p-type one, because they are electrically connected 
in series. In each single-leg MCTEM, the electric potential is almost kept constant along $\mathrm{y}-$ and $\mathrm{z}$-axis, and varies along $\mathrm{x}$-axis. The electric potential distribution at $\mathrm{xz}$ crosssection is shown in Figure $\mathbf{9 ( d )}$. The maximum electric potential of $6.41 \mathrm{mV}$ is obtained at the bottom of n-type single-leg MCTEM when $\Delta T$ is $35^{\circ} \mathrm{C}$. This value is the sum of electric potential values generated by $n$ - and p-type single-leg MCTEMs in this $\pi$-type module. In conclusion, the $n$ - and p-type single-leg modules in $\pi$-type MCTEM are thermally connected in parallel and electrically in series, while the thermoelectric slices in each single-leg MCTEM are electrically and thermally connected in parallel.

The $R_{\text {in }}, V, I$ and $P_{\max }$ of the $\pi$-type MCTEM at different $\Delta T$ are shown in Figure 10. Moreover, the performance of $\mathrm{n}$ - and p-type single-leg MCTEMs with $N_{\mathrm{n}}=N_{\mathrm{p}}=3$ has also been plotted here for comparison. The changing trends of $R_{\text {in }}, V, I$ and $P_{\max }$ with $\Delta T$ are the same observed in single-leg MCTEM, as presented in Figure 5. As it can be observed in these graphs, all parameters are increased with increasing $\Delta T$. In Figure 10(a), the $R_{\text {in }}$ of $\pi$-type MCTEM is ranging between 0.91 and $0.94 \mathrm{~m} \Omega$ in the whole $\Delta T$ range, which is much higher than that determined in n- or p-type single-leg MCTEM. In addition, it has been also found that this value is about $20 \%$ higher than the sum of $R_{\text {in }}$ of $\mathrm{n}$ - and p-type single-leg MCTEMs. As it was previously mentioned, $\Delta T_{\mathrm{e}}$ is only slightly different for $\pi$-type and single-leg MCTEMs. The higher $\Delta T_{\mathrm{e}}$ of $\pi$-type MCTEM leads to a relatively larger average electrical resistivity of thermoelectric materials, whose changing trend with temperature is shown in Figure S1. So, the $R_{\text {in }}$ shows the behavior mentioned above. Figure 10(b) shows the $V$ of $\pi$-type MCTEM, it changes from $0.9 \mathrm{mV}$ to $3.1 \mathrm{mV}$ when the $\Delta T$ varies from 10 to $35^{\circ} \mathrm{C}$, which is slightly higher than the electric potential sum of $n$ - and p-type single-leg MCTEMs. The increased $V$ is due to the electrical series connection of n- and p-type single-leg MCTEMs, and the little higher $\Delta T_{\mathrm{e}}$ of $\pi$-type MCTEM. Thus, the $V$ of $\pi$-type MCTEM 
is much higher than the observed in single-leg MCTEM at the same $\Delta T$. In other words, this series connection method of $\pi$-type structure can efficiently enhance $V$. Due to the significantly increased $R_{\text {in }}$ and slightly increased $V$, the $I$ of $\pi$-type MCTEM is slightly lower than the obtained for single-leg MCTEM, which is about $85.2 \%$ or $77 \%$ of that of n- or p-type single-leg MCTEM at $\Delta T=35^{\circ} \mathrm{C}$, respectively, as shown in Figure 10(c). Based on the above parameters, $P_{\max }$ has been calculated and displayed in Figure 10(d). The $P_{\max }$ of $\pi$-type MCTEM is obviously larger than the single-leg MCTEMs at different $\Delta T$, especially at larger $\Delta T$. The $P_{\max }$ of $\pi$-type MCTEM is $10.5 \mathrm{~mW}$, which is $75 \%$ and $61.5 \%$ larger than the observed in $\mathrm{n}$ - and p-type single-leg MCTEMs, respectively, at $\Delta T$ of $35^{\circ} \mathrm{C}$. So, the designed $\pi$-type MCTEM can effectively enhance the output voltage and also keep a large current and relatively low inner resistance, resulting in a higher output power.

Figure 11 plots the comparison between the performance of both $\pi$-type MCTEM and TTEM. It should be recalled that, these two modules have the same size of $5.5 \times 2 \times 5.6 \mathrm{~mm}^{3}$ whose schematics are shown in Figure 8. It is clearly noted that the $\pi$ type MCTEM has extremely lower $R_{\text {in }}$ and higher $I$, when compared to the TTEM one. Although the $V$ has been significantly enhanced by the design of $\pi$-type MCTEM, compared to single-leg MCTEM, as shown in Figure 10, it is still lower than the TTEM. The coordinated variation of $R_{\text {in }}, V$ and $I$, the $P_{\max }$ of $\pi$-type MCTEM is improved when compared with the values in the TTEM. The highest $P_{\max }$ value can reach $10.5 \mathrm{~mW}$, which is about 4.2 times larger than that of TTEM at $\Delta T=35^{\circ} \mathrm{C}$. For comparison purposes, the maximum output power density $\left(P_{\max }\right)$ of the $\pi$-type MCTEM obtained in this work is presented in Figure S4, together with the reported in the literature for thermoelectric modules with random materials and different sizes. The $P_{\max }$ of the $\pi$-type MCTEM enhances from $7.7 \mathrm{~mW} / \mathrm{cm}^{2}$ to $95.6 \mathrm{~mW} / \mathrm{cm}^{2}$ when the $\Delta T$ 
increases from $10{ }^{\circ} \mathrm{C}$ to $35^{\circ} \mathrm{C}$. Compared with the experimental ${ }^{23-26}$ and theoretical data $^{27,28}$, the $\pi$-type MCTEM has shown much higher $P_{\max }$. Thus, it is proved that the $\pi$-type MCTEM has much larger power output.

Based on its high power output, the electric power generated by the $\pi$-type MCTEM, in some applications where large amounts of waste heat are available, can be estimated. Taking into account the spent fuel pool for Daya Bay nuclear power plant with an area of $12.2 \times 9.9 \mathrm{~m}^{2}$, as an example ${ }^{29}$, the designed $\pi$-type MCTEMs can provide a $P_{\max }$ of about $115 \mathrm{~kW}$ at $\Delta T$ of $35^{\circ} \mathrm{C}$. This achieved electrical energy from the cooling water may support the cooling system to ensure the safe temperature of spent fuel. Thus, although this work is only a theoretical investigation, the novel high-power multilayer composite thermoelectric module will be a promising design to recover and reuse waste heat energy.

\section{Conclusion}

A novel $(\mathrm{Bi}, \mathrm{Sb})_{2} \mathrm{Te}_{3}$-based MCTEM with high output power is proposed for the first time, in the best of our knowledge, in this paper. For a single-leg MCTEM, a number of individual thermoelectric slices stacked together in parallel and contacted using inner and external electrodes. Based on the special structure, either the parallel connection of heat or electricity, are achieved, at same time, in this single-leg module. This new designed single-leg MCTEM shows an extremely low $R_{\text {in }}$ and relatively low $V$, leading to large $I$ and very high $P_{\max }$, when compared to single-leg TTEM. For further improving module performance, the effect of the number of thermoelectric slices has been studied. It has been found that the optimal $P_{\max }$ of $6 \mathrm{~mW}$ and $6.5 \mathrm{~mW}$ for $\mathrm{n}$ - and $\mathrm{p}$ type single-leg MCTEMs, respectively, are all obtained with 3 slices under different $\Delta T$. Using the optimized single-leg MCTEMs with $N_{\mathrm{n}}=N_{\mathrm{p}}=3$, a $\pi$-type MCTEM has been 
constructed to enhance $V$ and further improve $P_{\max }$. At $\Delta T=35^{\circ} \mathrm{C}$, the designed $\pi$-type MCTEM obtains a very large $V$ of $3.1 \mathrm{mV}, I$ of $3.3 \mathrm{~A}$, and relatively low $R_{\text {in }}$ of 0.94 $\mathrm{m} \Omega$, resulting in a high $P_{\max }$ of $10.5 \mathrm{~mW}$. The obtained $P_{\max }$ is 4.2 times larger than that of $\pi$-type TTEM. To summarize, the novel $(\mathrm{Bi}, \mathrm{Sb})_{2} \mathrm{Te}_{3}$-based MCTEM is a promising configuration for obtaining very high output power, which would be highly beneficial for commercializing high-power thermoelectric devices.

\section{Acknowledgements}

The work is financially supported by National Key R\&D Program of China of 2017YFE0195200, the National Basic Research Program of China of 2013CB632506, the Natural Science Fund of China under grant Nos. 51871134, 51672159, the Science Fund of Shandong Province under grant No. ZR2019MEM007, the Young Scholars Program of Shandong University under grant No. 2015WLJH21, and the Foundation of the State Key Laboratory of Metastable Materials Science and Technology under grant No.201703.

M. A. Madre and A. Sotelo acknowledge Gobierno de Aragón-FEDER (Research Group T54-17R) and MINECO-FEDER (MAT2017-82183-C3-1-R) for funding. 


\section{References:}

1. $\quad$ S. Sorrell, Renewable and Sustainable Energy Reviews, 2015, 47, 74-82.

2. X. Zhang and L. Zhao, Journal of Materiomics, 2015, 1, 92-105.

3. K. Zeb, S. M. Ali, B. Khan, C. A. Mehmood, N. Tareen, W. Din, U. Farid and A. Haider, Renewable and Sustainable Energy Reviews, 2017, 75, 1142-1155.

4. W. Liu, Q. Jie, H. Kim and Z. Ren, Acta Materialia, 2015, 87, 357-376.

5. L. Yang, Z. Chen, M. Dargusch and J. Zou, Advanced Energy Materials, 2018, 8, 1701797.

6. A. Fabián-Mijangos, G. Min and J. Alvarez-Quintana, Energy Conversion and Management, 2017, 148, 1372-1381.

7. X. Hu, P. Jood, M. Ohta, M. Kunii, K. Nagase, H. Nishiate, M. G. Kanatzidis and A. Yamamoto, Energy \& Environmental Science, 2016, 9, 517-529.

8. Q. Zhang, J. Liao, Y. Tang, M. Gu, C. Ming, P. Qiu, S. Bai, X. Shi, C. Uher and L. Chen, Energy \& Environmental Science, 2017, 10, 956-963.

9. X. Wang, H. Wang, W. Su, F. Mehmood, J. Zhai, T. Wang, T. Chen and C. Wang, Renewable Energy, 2019, 141, 88-95.

10. S. Fan and Y. Gao, Energy, 2018, 150, 38-48.

11. H. Liu, J. Meng, X. Wang and W. Chen, Energy Conversion and Management, 2018, 175, 11-20.

12. H. Suda, T. Nemoto, J. Sato, Japan Pat., CN:201480041720:A, 2018.

13. S. Fan, J. Zhao, J. Guo, Q. Yan, J. Ma and H. H. Hng, Applied Physics Letters, 2010, 96, 182104.

14. J. Yang, F. Wu, Z. Zhu, L. Yao, H. Song and X. Hu, Journal of Alloys and Compounds, $2015,619,401-405$.

15. B. Poudel, Q. Hao, Y. Ma, Y. C. Lan, A. Minnich, B. Yu, X. Yan, D. Wang, A. Muto, D. Vashaee, X. Chen, J. Liu, M. Dresselhaus, G. Chen, Z. F. Ren, Science, 2008, 320, 634-638.

16. L. Hu, H. Wu, T. Zhu, C. Fu, J. He, P. Ying and X. Zhao, Advanced Energy Materials, 
$2015, \mathbf{5}, 1500411$.

17. C. Huang, B. Chen, K. Chen, C. Hsueh, W. Wei and C. Lee, International Journal of Applied Ceramic Technology, 2015, 12, 451-460.

18. H. C. Song, J. E. Zhou, D. Maurya, Y. Yan, Y. U. Wang and S. Priya, Sci Rep, 2017, 7, 12353.

19. S. H. Park, Y. Jin, J. Cha, K. Hong, Y. Kim, H. Yoon, C.-Y. Yoo and I. Chung, ACS Applied Energy Materials, 2018, 1, 1603-1611.

20. B. Zhang, T. Zheng, Q. Wang, Z. Guo, M. J. Kim, H. N. Alshareef and B. E. Gnade, Scripta Materialia, 2018, 152, 36-39.

21. Y. Sakabe, Current Opinion in Solid State and Materials Science, 1997, 2, 4.

22. S. Ferreira-Teixeira and A. M. Pereira, Energy Conversion and Management, 2018, 169, 217-227.

23. H. Choi, S. Kim, Y. Kim, J. We, M. Oh and B. Cho, Journal of Materials Chemistry C, $2017, \mathbf{5}, 8559-8565$.

24. Z. Zhou, D. Zhu, H. Wu and H. Zhang, Journal of Thermal Science, 2013, 22, 48-54.

25. S. Park, S. Jo, B. Kwon, F. Kim, H. Ban, J. Lee, D. Gu, S. Lee, Y. Hwang, J. Kim, D. Hyun, S. Lee, K. Choi, W. Jo and J. Son, Nat Communcation, 2016, 7, 13403.

26. H. Böttner, J. Nurnus, A. Schubert, F. Volkert, International Conference on Thermoelectrics, 2007.

27. S. Kim, h. Choi, Y. Kim, J. We, J. Shin, H. Lee, M. Oh, K. Lee, B. Cho, Nano Energy, 2017, 31, 258-263.

28. G. M. D.M. Rowe, Journal of Power Sources, 1998, 73, 193-198.

29. D. Wang, I. Gauld, G. Yoder, L. Ott, G. Flanagan, M. Francis, E. Popov, J. Carbajo, P. Jain, J. Wagner and J. Gehin, Nuclear Technology, 2017, 180, 205-215. 
Figure 1. Schematics of the n-type (a) single-leg multilayer composite thermoelectric module (single-leg MCTEM) and (b) traditional single-leg thermoelectric module (single-leg TTEM). The cold-side temperature is fixed at $25^{\circ} \mathrm{C}$ and the hot-side temperature changes from $35^{\circ} \mathrm{C}$ to $60^{\circ} \mathrm{C}$.

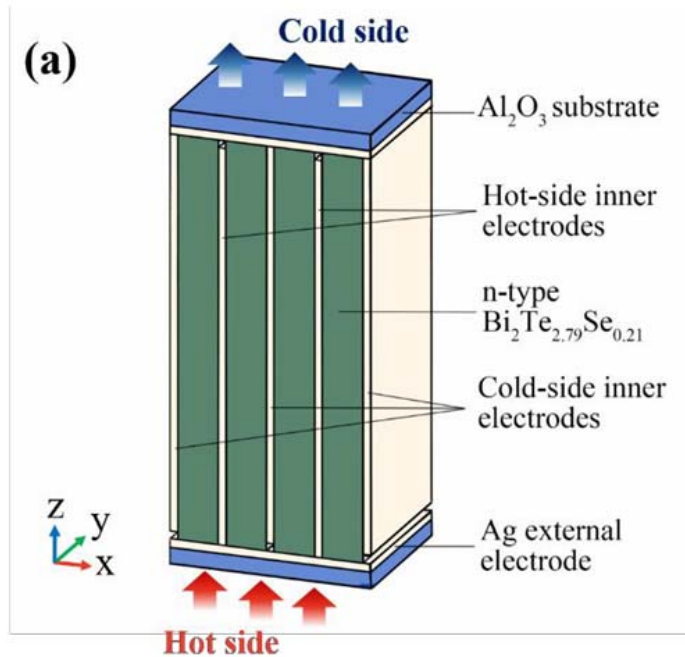

Hot side

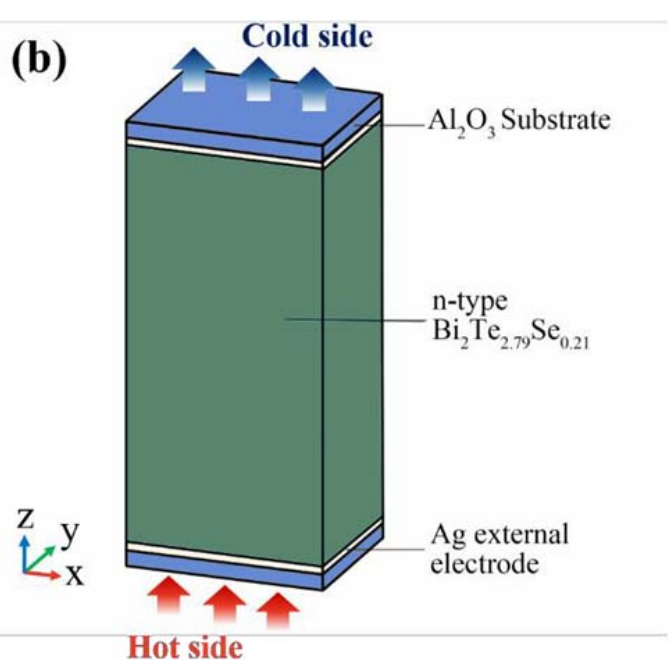

Hot side 
Figure 2. The (a) temperature distribution for the n-type single-leg MCTEM at $\Delta T=35$

${ }^{\circ} \mathrm{C}$ under open-circuit condition. (b) The temperature distribution at xy cross-section under open-circuit condition when the height $\left(l_{z}\right)$ is $2.8 \mathrm{~mm}$ and $\Delta T$ is $35^{\circ} \mathrm{C}$. (c) The effective hot- and cold-side temperatures as a function of the $\Delta T$.

(a)

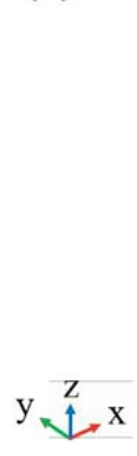

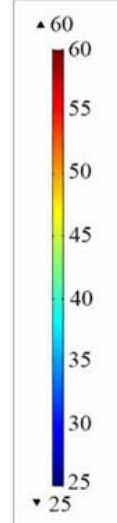

(b)

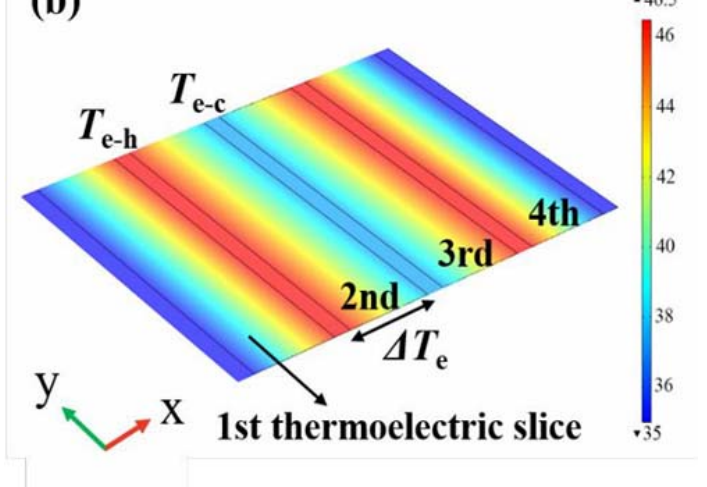

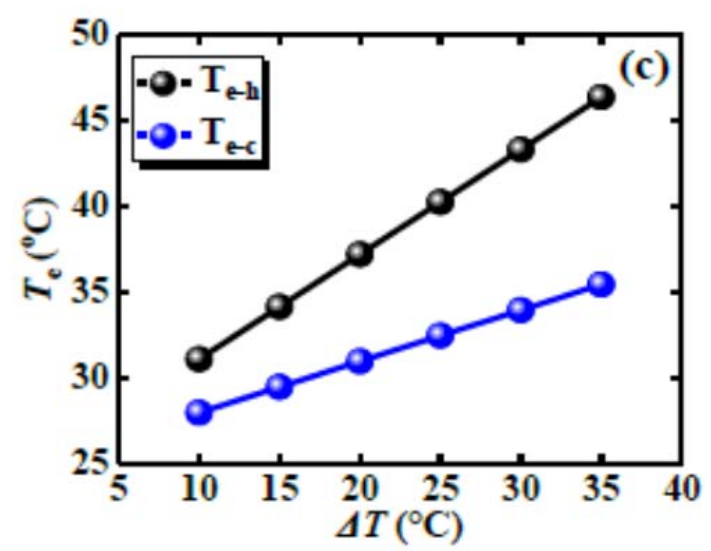


Figure 3. The (a) electric potential distribution for the n-type single-leg MCTEM at $\Delta T$ $=35^{\circ} \mathrm{C}$. (b) The electric potential distribution at xy cross-section when the $l_{\mathrm{z}}$ is $2.8 \mathrm{~mm}$ and $\Delta T$ is $35^{\circ} \mathrm{C}$.

(a)
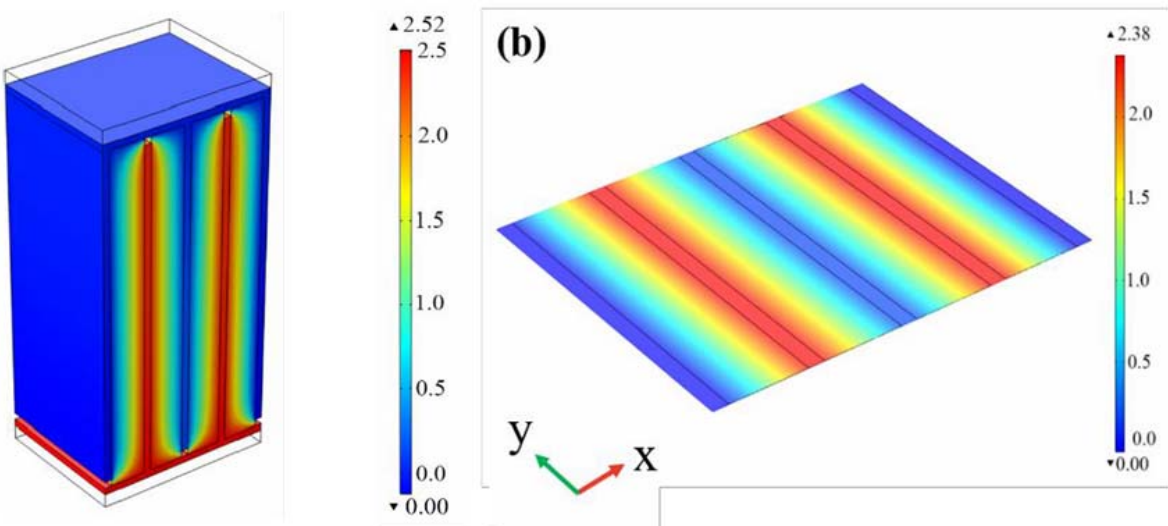
Figure 4. (a) The output voltage, (b) output power of the n-type single-leg MCTEM as a function of working current under different $\Delta T$.
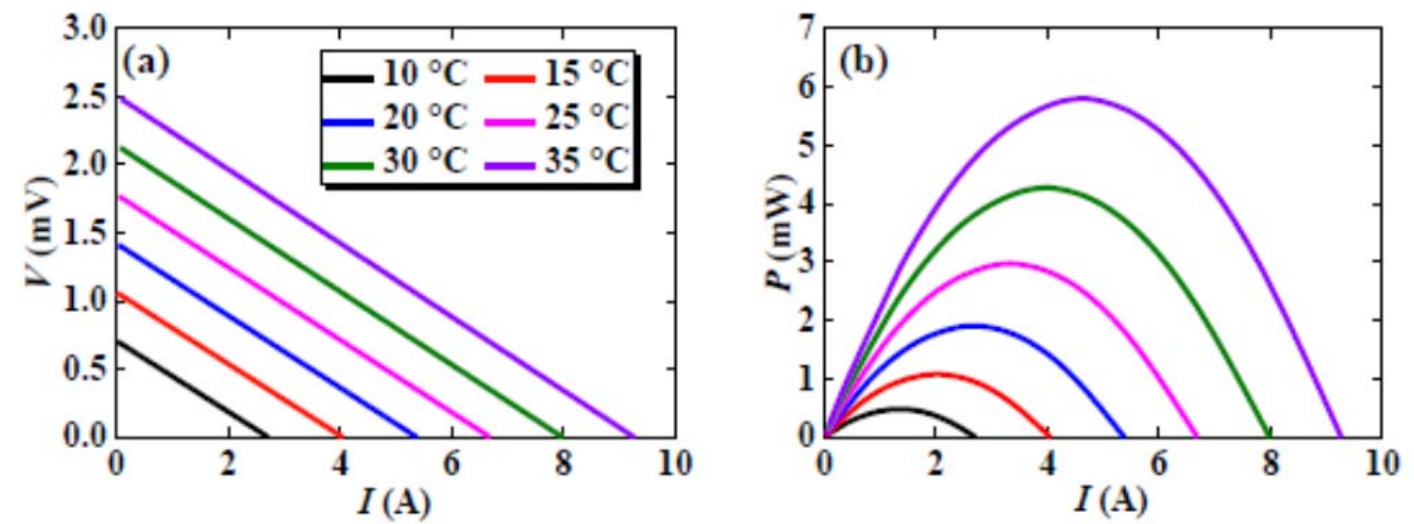
Figure 5. (a) The inner resistance, (b) output voltage, (c) working current and (d) maximum output power for the n-type single-leg MCTEM and single-leg TTEM as a function of $\Delta T$ at matched load condition.
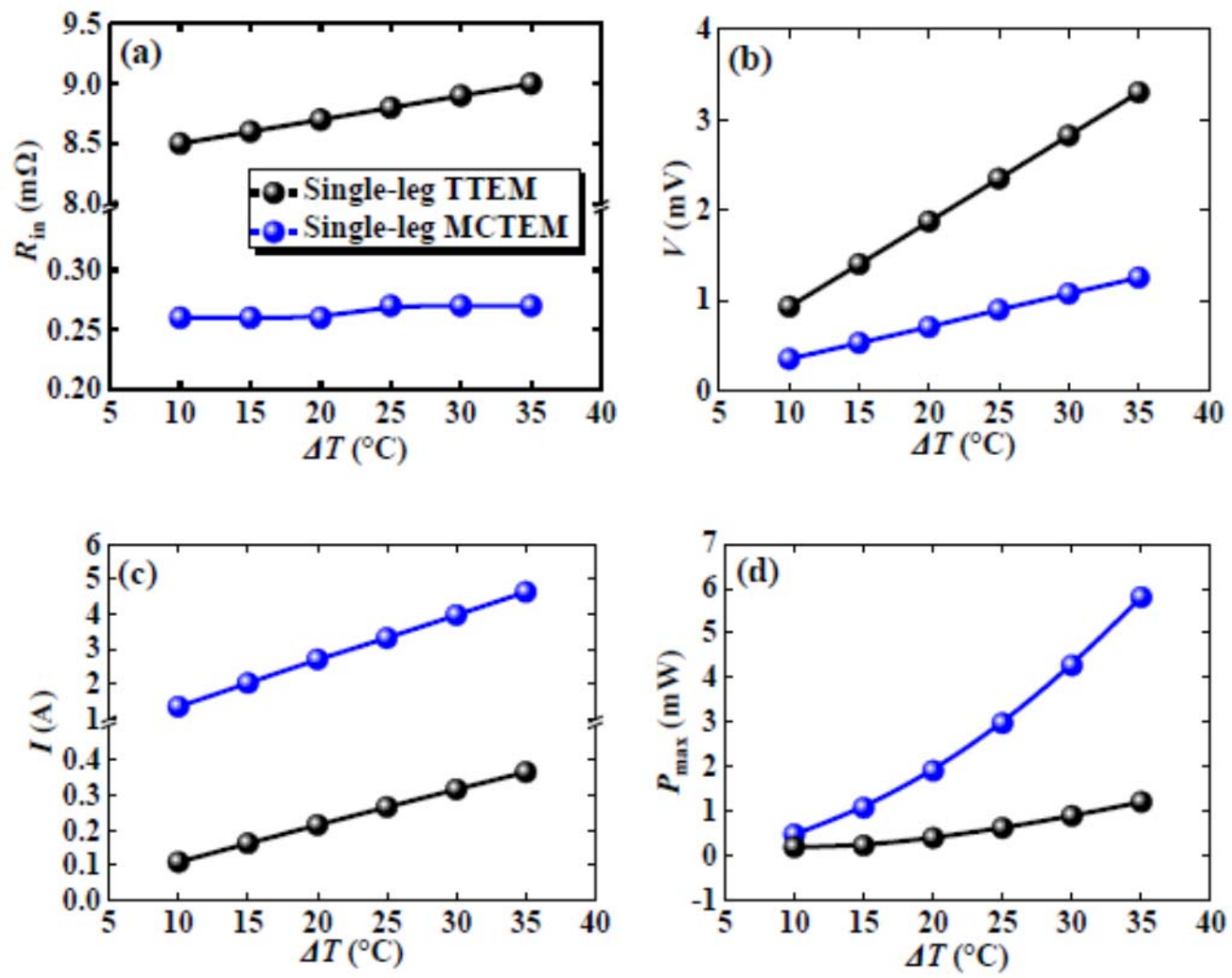
Figure 6. (a) The temperature distribution of the 1st thermoelectric slice for n-type single-leg MCTEM at the xz cross-section when the number of thermoelectric material slices $\left(N_{\mathrm{n}}\right)$ are 2, 4,6 and 8. (b) The effective hot- and cold-side temperatures of the 1st thermoelectric slice for n-type single-leg MCTEM as a function of $N_{\mathrm{n}}$ when $\Delta T$ is $35^{\circ} \mathrm{C}$.
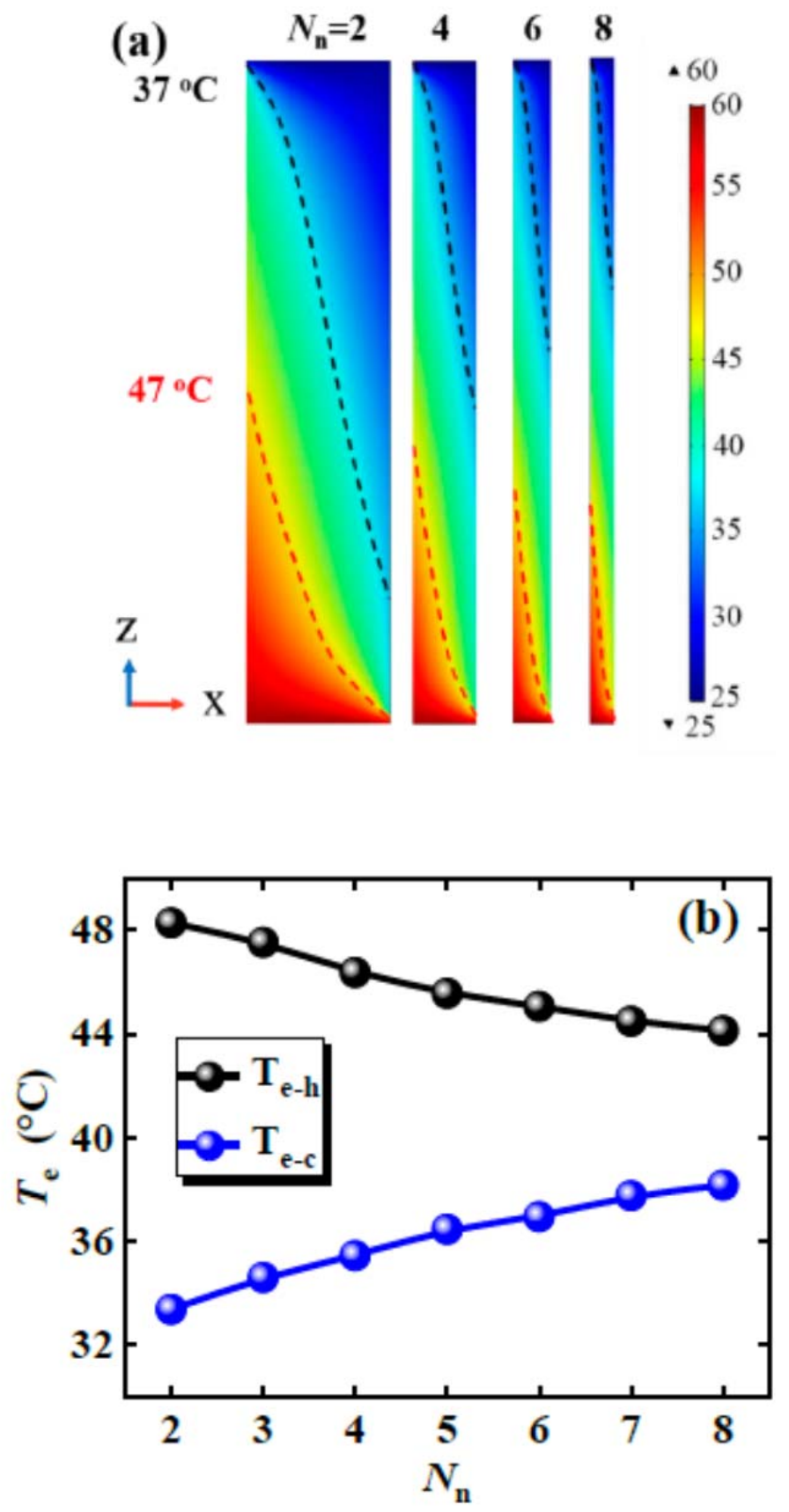
Figure 7. (a) The inner resistance, (b) output voltage, (c) working current and (d) maximum output power of the n-type single-leg MCTEM as a function of $N_{\mathrm{n}}$ under different $\Delta T$.
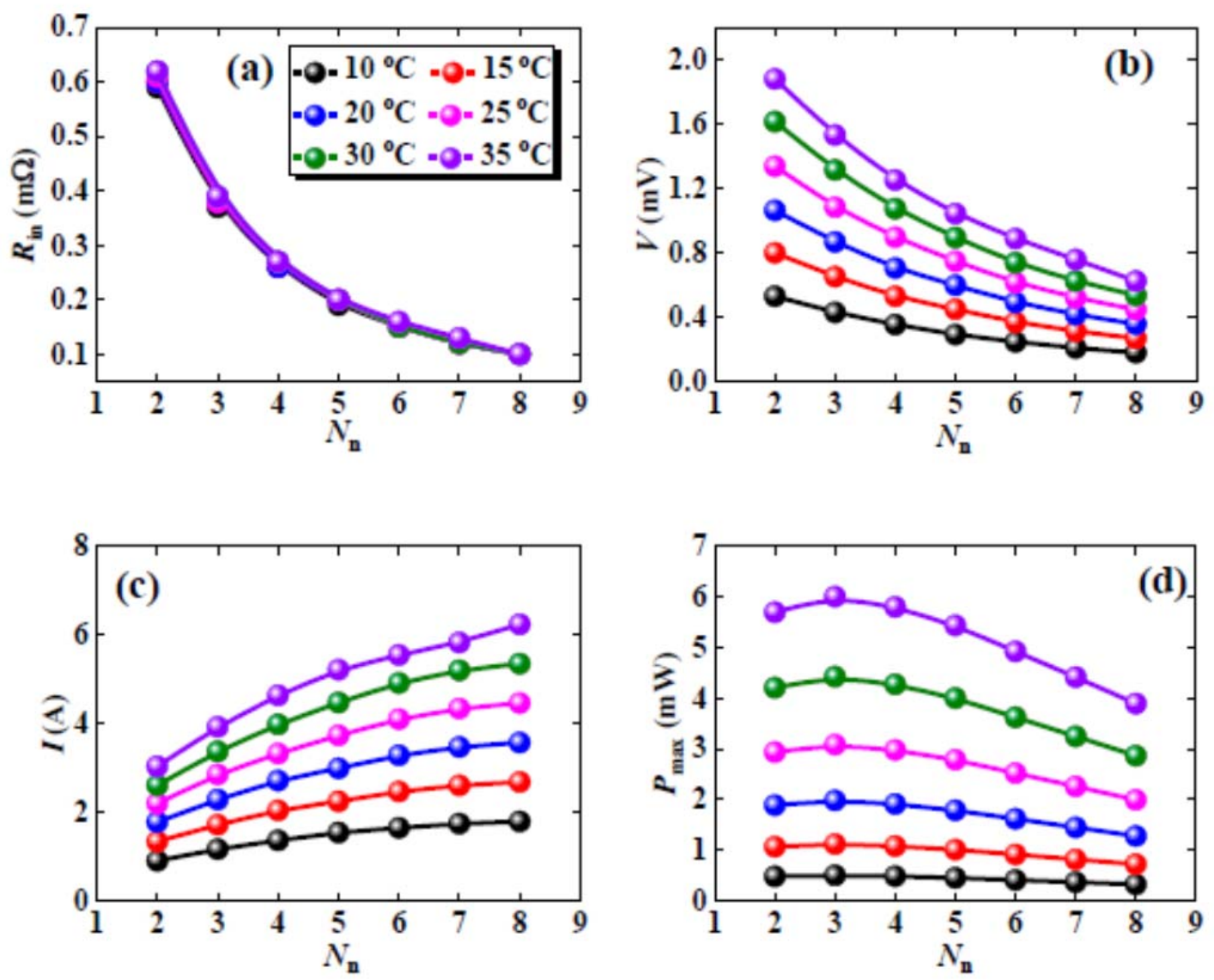
Figure 8. Schematics of the (a) $\pi$-type multilayer composite thermoelectric module $(\pi$ type MCTEM) and (b) $\pi$-type traditional thermoelectric module ( $\pi$-type TTEM).

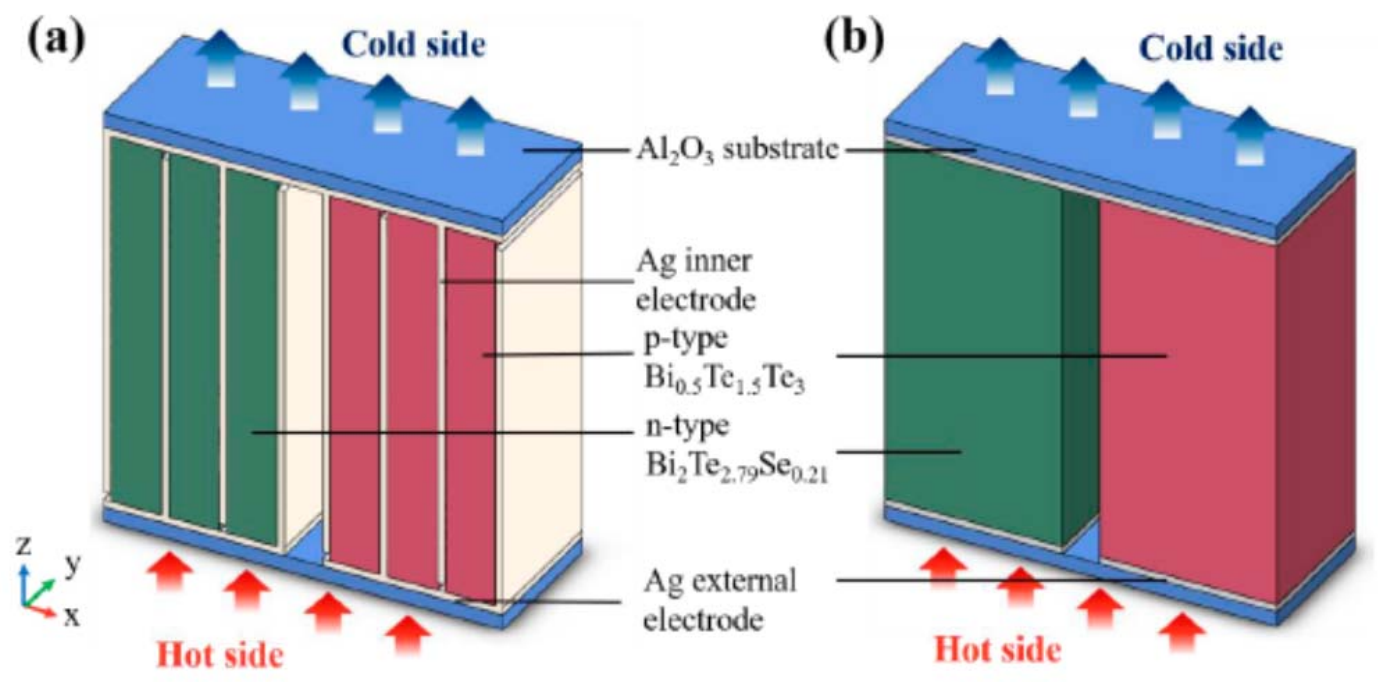


Figure 9. The (a) temperature and (c) electric potential distribution in $\pi$-type MCTEM under open-circuit condition when $\Delta T$ is $35^{\circ} \mathrm{C}$. The (b) temperature and (d) electric potential distribution in $\pi$-type MCTEM at the xz cross-section under open-circuit condition when $\Delta T$ is $35^{\circ} \mathrm{C}$.

(a)
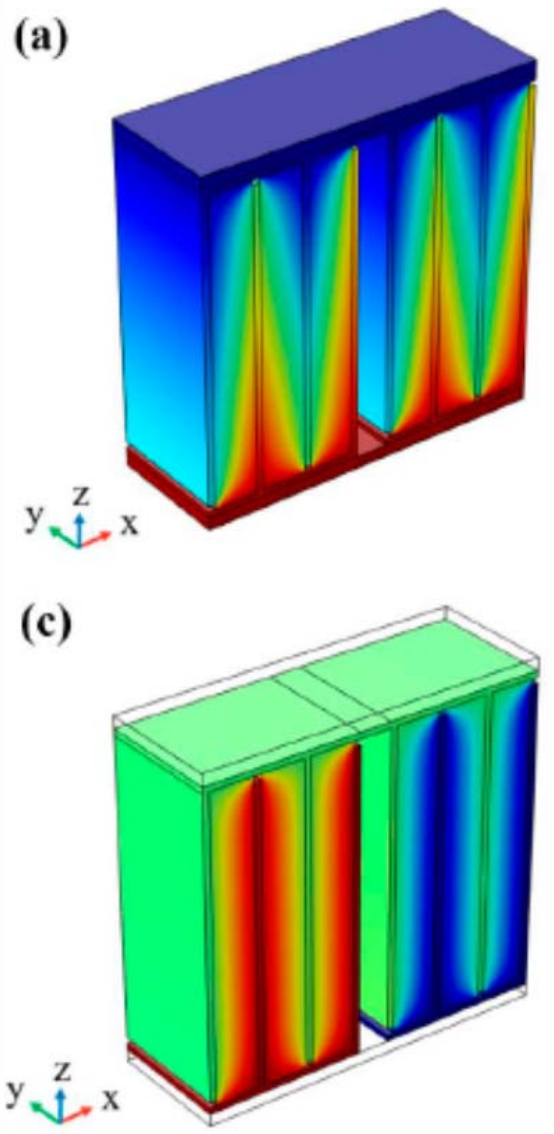

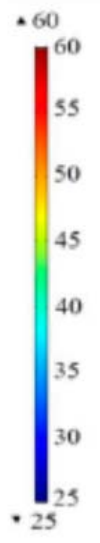

(b)

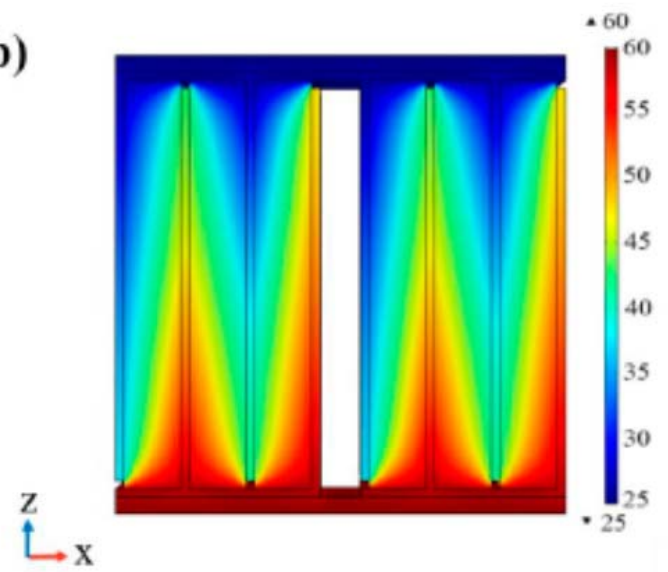

(d)
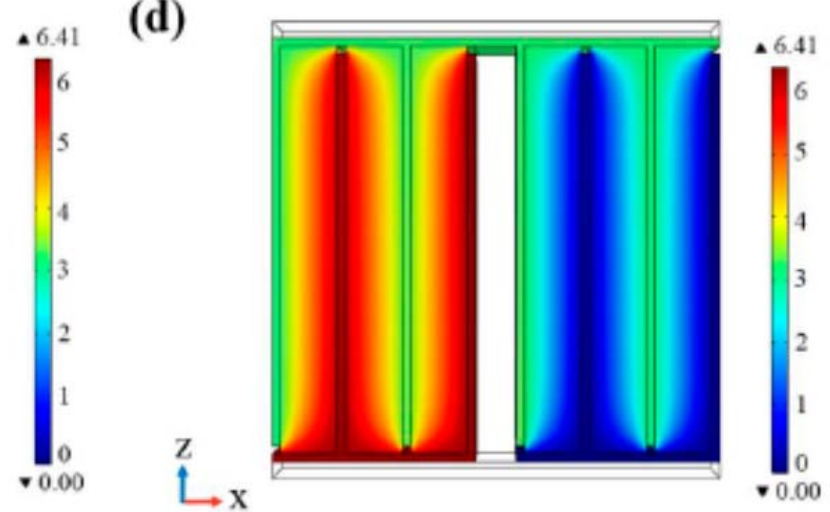
Figure 10. (a) The inner resistance, (b) output voltage, (c) working current (d) maximum output power of the $\pi$-type MCTEM, n-type single-leg MCTEM and p-type single-leg MCTEM as a function of $\Delta T$.
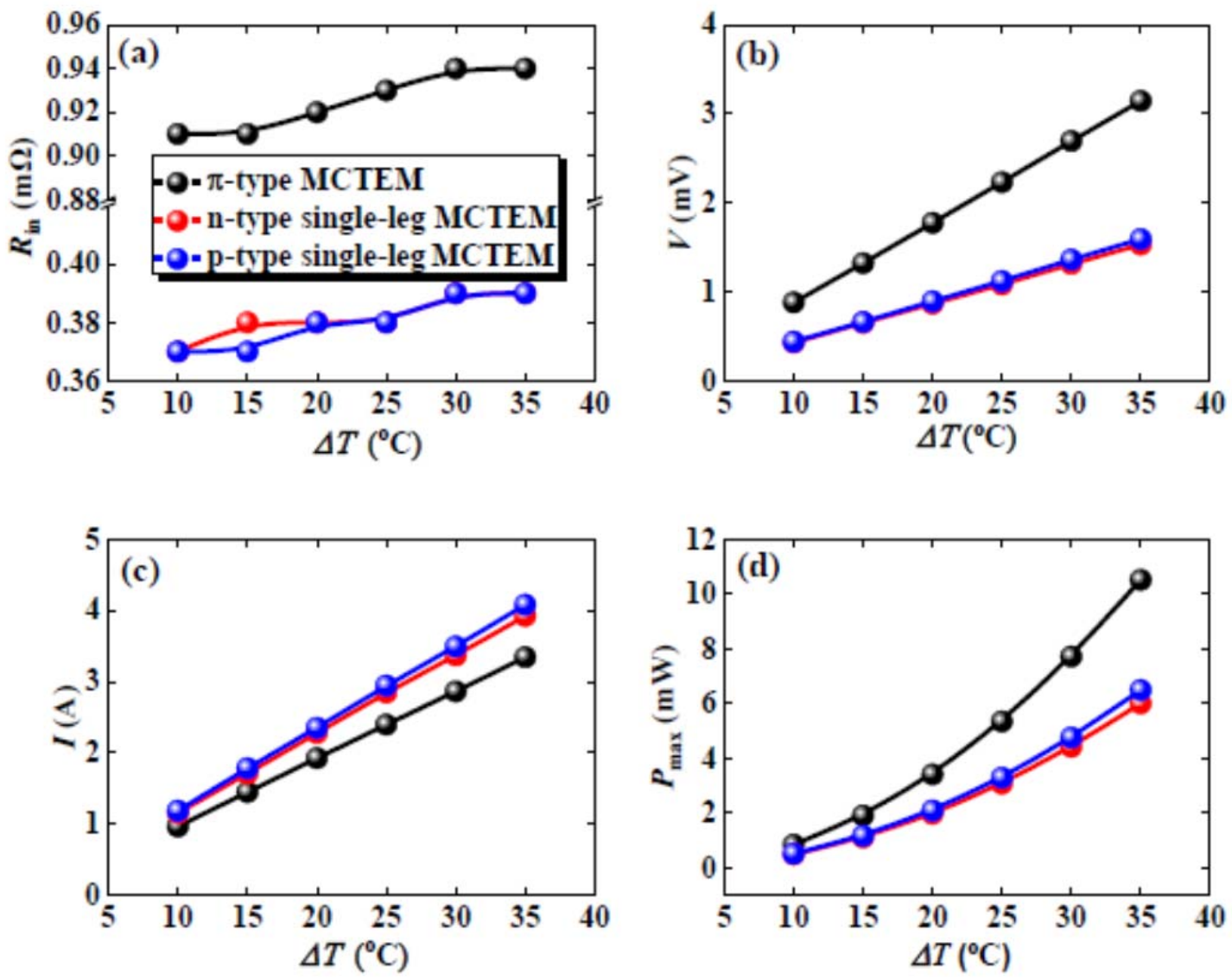
Figure 11. (a) The inner resistance, (b) output voltage, (c) working current and (d) maximum output power of the $\pi$-type MCTEM and $\pi$-type TTEM as a function of $\Delta T$.
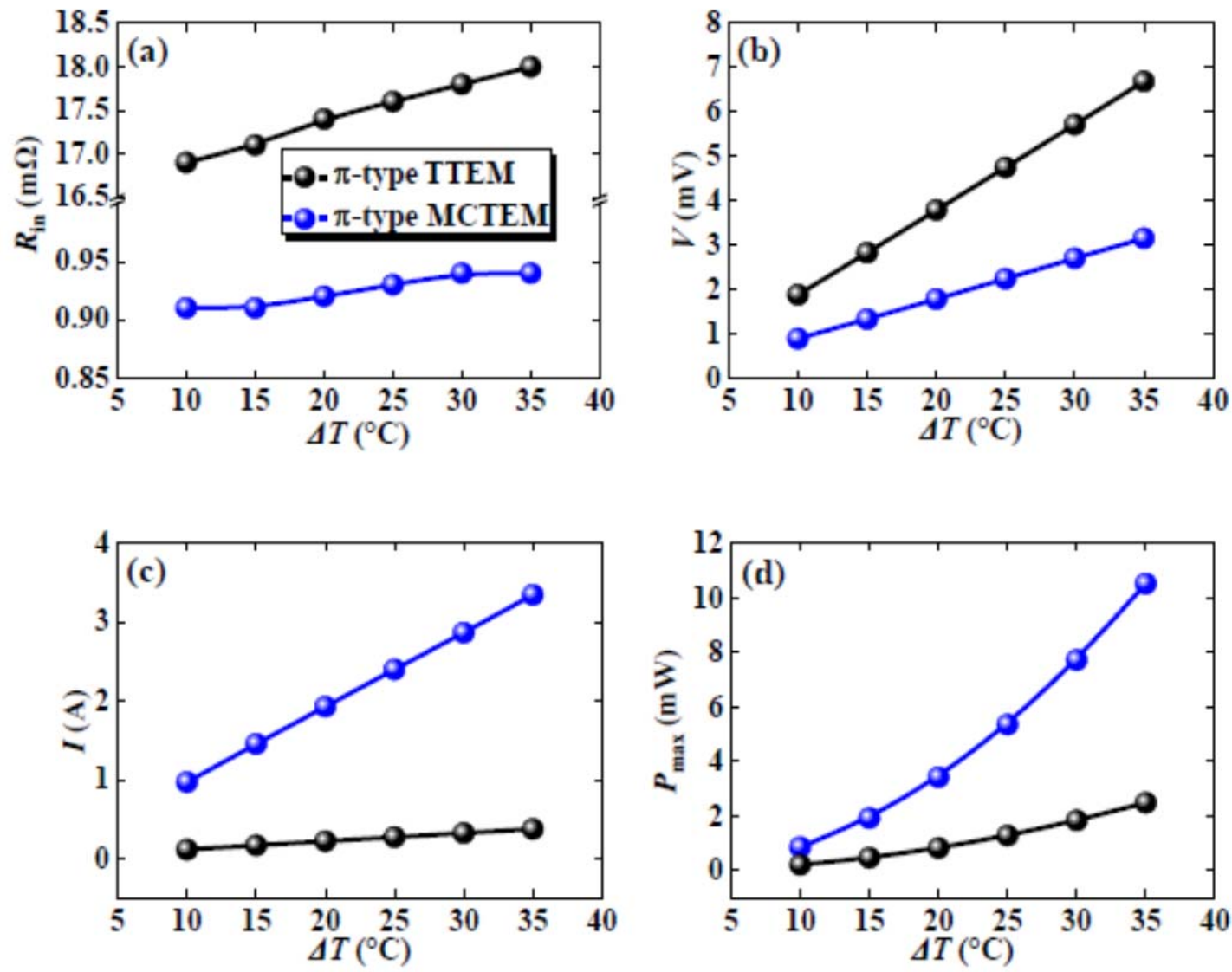
Figure S1. The temperature dependence of (a) electrical conductivity, (b) Seebeck coefficient, (c) thermal conductivity and (d) figure of merit for p-type $\mathrm{Bi}_{0.5} \mathrm{Sb}_{1.5} \mathrm{Te}_{3}$ and n-type $\mathrm{Bi}_{2} \mathrm{Te}_{2.79} \mathrm{Se}_{0.21}$.
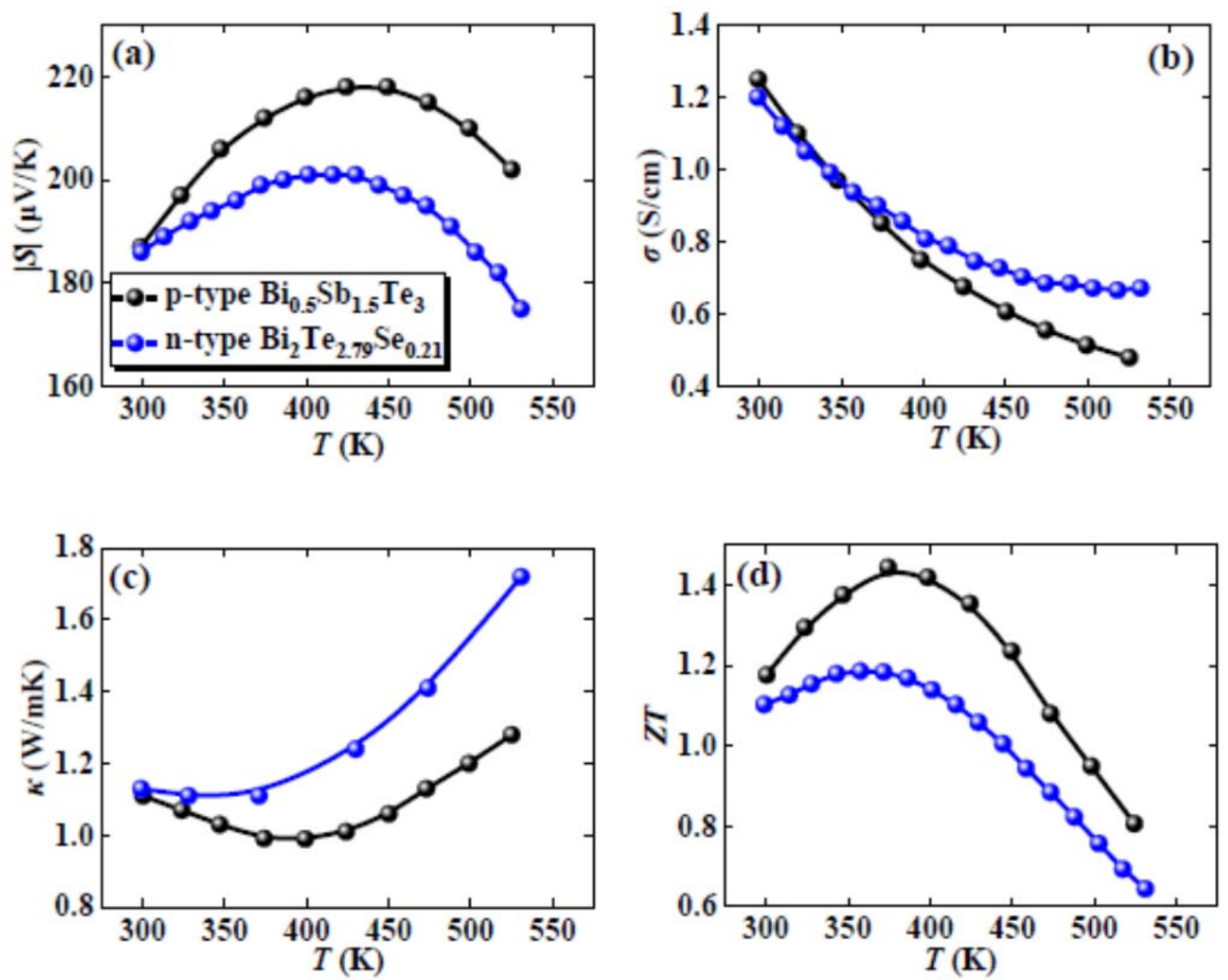
Figure S2. The (a) temperature and (b) electric potential distributions for the n-type traditional single-leg thermoelectric module at $\Delta T=35^{\circ} \mathrm{C}$.

(a)

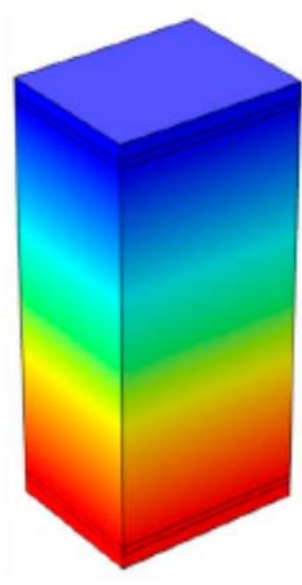

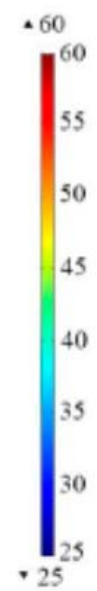

(b)

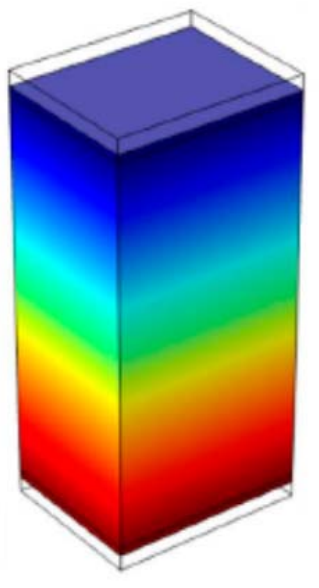

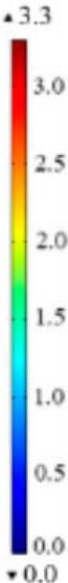


Figure S3. (a) The inner resistance, (b) output voltage, (c) working current and (d) maximum output power of the p-type single-leg multilayer composite thermoelectric module (MCTEM) as a function of the $N_{\mathrm{p}}$ under different $\Delta T \mathrm{~s}$.
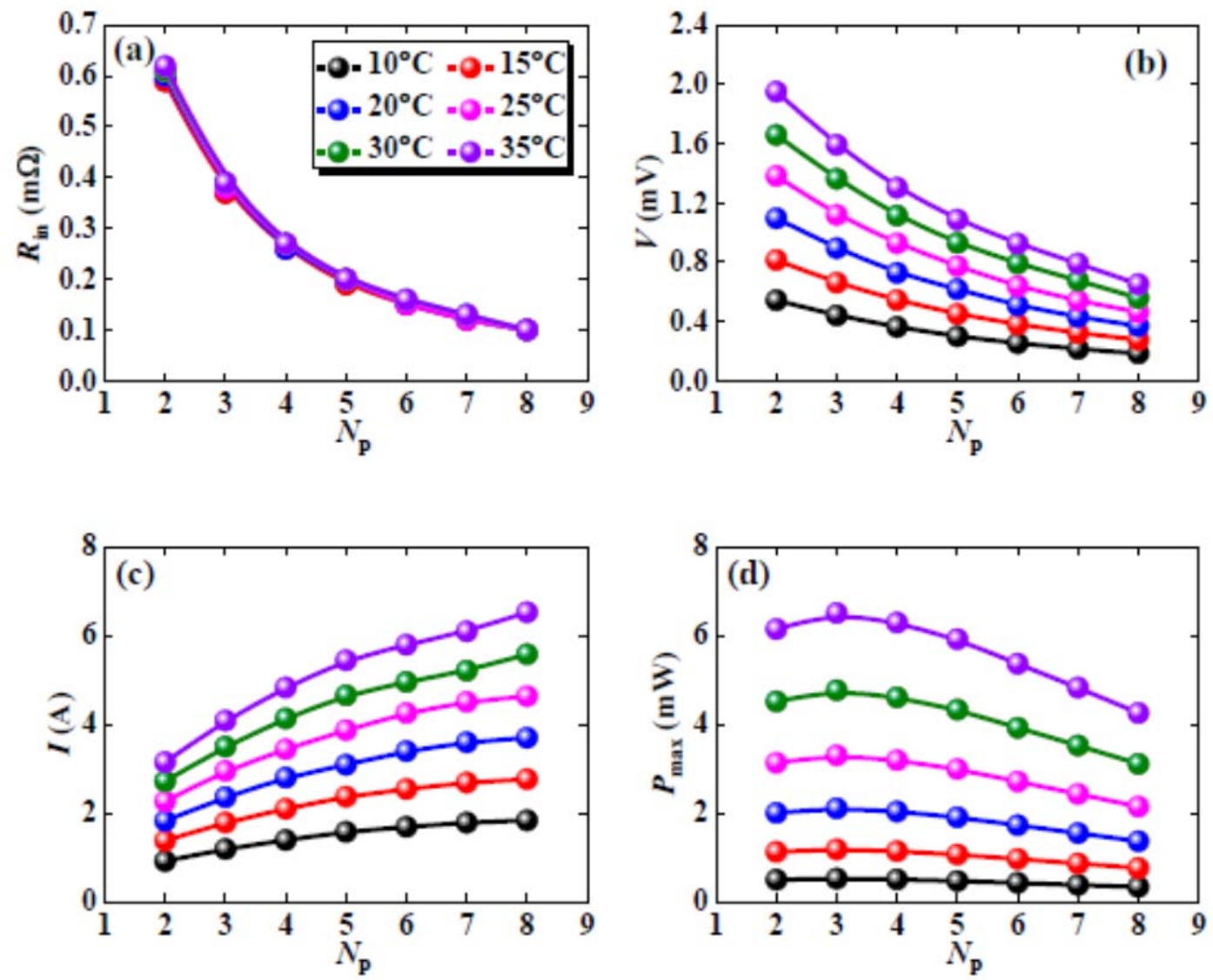
Figure S4. Maximum output power density as a function of $\Delta T$ for the $\pi$-type MCTEM and previously reported modules. The data marked by solid and open symbols are obtained from experimental and theoretical articles, respectively.

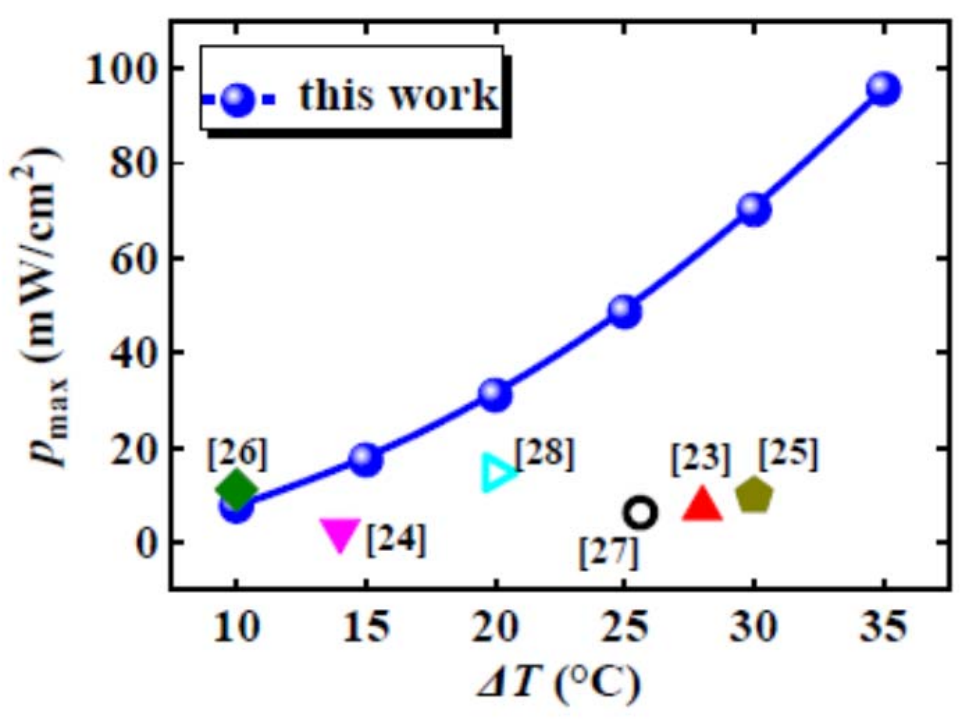


Table S1. Physical properties of $\mathrm{Cu}$ and $\mathrm{Al}_{2} \mathrm{O}_{3}$

\begin{tabular}{ccccc}
\hline & $\begin{array}{c}C_{\mathrm{p}} \\
\end{array}$ & $\boldsymbol{\rho}$ & $\sigma$ & $\boldsymbol{\kappa}$ \\
& $\left(\mathbf{J} / \mathbf{k g}^{*} \mathbf{K}\right)$ & $\left(\mathbf{k g} / \mathbf{m}^{3}\right)$ & $\left(\times \mathbf{1 0} 0^{6} \mathrm{~S} / \mathbf{m}\right)$ & $(\mathbf{W} / \mathbf{m} * \mathbf{K})$ \\
\hline $\mathrm{Cu}$ & 384 & 8960 & 58.1 & 401 \\
$\mathrm{Al}_{2} \mathrm{O}_{3}$ & 730 & 3965 & 0 & 35 \\
\hline
\end{tabular}

